\title{
Syndecan-1 (CD138) Immunoreactivity in Bone Marrow Biopsies of Multiple Myeloma: Shed Syndecan-1 Accumulates in Fibrotic Regions
}

Ilene B. Bayer-Garner, M.D., Ralph D. Sanderson, Ph.D., Madhav V. Dhodapkar, M.D., Rebecca B. Owens, M.T., Carla S. Wilson, M.D., Ph.D.

Department of Pathology (IBB-G, RDS, RBO, CSW) and Department of Anatomy and the Arkansas Cancer Research Center (RDS), University of Arkansas for Medical Sciences, Little Rock, Arkansas; and Laboratory of Cellular Physiology and Immunology (MVD), Rockefeller University, New York, New York

Syndecan-1 (CD138) mediates myeloma cell adhesion, and loss of syndecan-1 from the cell surface may contribute to myeloma proliferation and dissemination. Flow cytometry analysis of myeloma cells in bone marrow specimens shows heterogeneity in cell surface syndecan-1 expression. It is not known whether weaker expression correlates with more aggressive disease. However, recent reports suggest that variations in syndecan-1 staining intensity on myeloma cells may be an artifact of specimen handling. In this study, we evaluate syndecan-1 expression in bone marrow biopsy sections from 28 multiple myeloma patients, to elucidate the heterogeneity of syndecan-1 expression in situ. Immunoreactivity for syndecan-1, using the antibody B-B4 (CD138), was found in more than $95 \%$ of multiple myeloma cells in 27 of 28 biopsies. However, one biopsy had more than $50 \%$ CD138-negative cells and cells with weak CD138 expression were identified in the majority of cases. Loss of syndecan-1 did not appear to relate to myeloma cell differentiation. In addition, syndecan-1 was detected on intravascular and intrasinusoidal myeloma cells suggesting that loss of syndecan-1 may not be required for extramedullary dissemination. Bone marrow biopsies from nine additional patients, with variable CD138 staining intensity on myeloma cells as determined by flow cytometry, were studied by immunohistochemistry. The heterogenous CD138 expression was confirmed in

Copyright (C) 2001 by The United States and Canadian Academy of Pathology, Inc.

VOL. 14, NO. 10, P. 1052, 2001 Printed in the U.S.A.

Date of acceptance: June 27, 2001.

Address reprint requests to: Ilene B. Bayer-Garner, M.D., Department of Pathology, Slot 517, University of Arkansas for Medical Sciences, 4301 West Markham Street, Little Rock, AR 72205; e-mail: bayerileneb@ uams.edu; fax: 501-686-6352. situ, with weakly positive cells concentrated in areas of reticulin fibrosis. These cells had a disrupted pattern of membrane staining in contrast to the strong linear membrane staining seen in the other multiple myeloma cells. In addition, the fibrotic stroma stained intensely for syndecan-1. Accumulation of syndecan-1 within the extracellular matrix of the marrow likely is derived by shedding of the molecule from the surface of myeloma cells. Because syndecan-1 can act to regulate the activity of heparan-binding growth factors, these reservoirs of syndecan-1 may play a critical role in promoting myeloma pathogenesis, or in regeneration of the tumor after chemotherapy.

KEY WORDS: B-B4, CD138, Flow cytometry, Immunohistochemistry, Multiple myeloma, Syndecan-1.

Mod Pathol 2001;14(10):1052-1058

Syndecans are a family of cell surface proteoglycans of which syndecan-1 is the prototypical member. Syndecan- 1 is expressed on cells from human myeloma cell lines, and mediates cell-cell adhesion, adhesion to type I collagen, and inhibition of invasion into type I collagen gels (1-3). Cells lacking syndecan- 1 expression adhere poorly to one another, but after their transfection with the syndecan-1 cDNA, these cells form tight cell-cell adhesions (3). Additionally, cells that normally invade type I collagen gels are rendered noninvasive after their transfection with syndecan-1 cDNA, thus providing direct evidence that loss of syndecan-1 expression on the cell surface may be an essential element in the process of multiple myeloma (MM) cell invasion (2). This is supported by studies in scid mice, whereby syndecan-1 expression on the cell surface inhibits tumor growth and delays development of myeloma-related morbidity (4). 
The cell surface monoclonal antibodies B-B4 and MI15, recognize epitopes of syndecan- 1 within the cluster designation CD138 (5, 6). Evaluation of B-B4 and MI15 by immunohistochemistry (IHC) techniques in paraffin-embedded bone marrow (BM) biopsy sections shows staining in all cases of plasma cell dyscrasias and many Hodgkin's lymphomas with classic Reed-Sternberg cells $(5,7)$. Analysis of MM by flow cytometry (FCM), in both cell lines and inpatient specimens, shows heterogeneous B-B4 expression among myeloma cells within specimens $(4,6,8-11)$. This heterogeneous expression may be due to syndecan-1 shedding from the cell surface, with loss of syndecan-1 being a possible requirement for intravascular invasion. Syndecan-1 is shed from myeloma cells and accumulates in the serum of myeloma patients (12). Shed syndecan-1 is composed of an intact ectodomain that contains the extracellular portion of the core protein with attached heparan sulfate chains, and thus remains biologically active. A recent study shows that soluble syndecan-1 from myeloma patients exists in a complex with hepatocyte growth factor and therefore may act to regulate the biologic activity of this and other heparin-binding cytokines (13). In addition, elevated levels of serum syndecan-1 correlate with increased tumor mass and decreased patient survival $(12,14)$.

The heterogeneous syndecan-1 expression by myeloma cells may relate to shedding of the molecule and this may result in differential syndecan-1 expression on myeloma cell surfaces. However, Jourdan et al. suggest that loss of CD138 seen by FCM analysis may be the result of myeloma cell apoptosis induced by prolonged specimen handling (15). Therefore, in the present study, syndecan-1 expression is examined in BM biopsies that were immediately fixed in Zenker's solution to ensure optimal epitope recovery. BM sections from 28 patients with progressive (evolutive) MM are reviewed for specificity and distribution of CD138 staining. Variations in CD138 expression on myeloma cells evident by FCM analysis are also compared with IHC in nine additional patient specimens.

\section{MATERIALS AND METHODS}

Zenker-fixed paraffin embedded BM biopsies, from 28 patients with progressive $\mathrm{MM}$ and greater than $30 \%$ plasma cells, were obtained from the Department of Pathology tissue files at the University of Arkansas for Medical Sciences. The cases were graded based on the Bartl et al. classification of MM cell types as follows: grade I, low grade (Marschalko, small cell); grade II, intermediate grade (asynchronous, polymorphous, cleaved); and grade III, high grade (plasmablastic) (16). Nine additional BM biopsies from patients with previous FCM analysis (described below) were also examined. These biopsies were stained for reticulin fibrosis, which was quantitated utilizing a scoring system described by Bauermeister (17).

\section{Immunohistochemical Techniques}

Three micron sections were cut and mounted on 3-aminopropyltrethoxy-silane-coated slides, dried, and deparaffinized before undergoing antigen retrieval by heat treatment in DAKO Target Retrieval solution (DAKO, Carpenteria, CA). Endogenous peroxidase activity was quenched with $0.3 \%$ peroxidase and nonspecific binding was quenched with horse serum block (Oncogene Research Products, Cambridge, MA). The DAKO Large Volume LSAB2 Alkaline Phosphatase Kit (DAKO) was used with 1:100 dilution of antibody to CD138 (clone B-B4, Serotec, Raleigh, NC), a mouse anti-human antibody, which recognizes an epitope of human syndecan-1 $(7,18)$. Sections were incubated with biotinylated secondary antibody for 30 minutes, and then with streptavidin alkaline phosphatase for 30 minutes. The signal was visualized with DAKO Fast Red Substrate System (DAKO) yielding a red end product at the site of the target antigen. Positive control tissue consisted of normal skin in which cell membrane immunoreactivity for CD138 was evident in the basal and granular layers of keratinocytes, as previously reported $(19,20)$. The negative control consisted of a 1:100 dilution of a nonspecific isotype-matched IgG $_{1}$ mouse antibody, MCA 928 (Serotec), which was substituted for CD138. The pattern of CD138 staining and percent MM cells expressing CD138 were evaluated by two authors (IBG, CSW). The nine biopsies with FCM analysis were also evaluated for the percent MM cells with strongly positive CD138 immunostaining, either more than $95 \%$, 80 to $95 \%$, or less than $80 \%$ and for stromal CD138 deposition (0 scant, 1+ mild, 2+ moderate/abundant). FCM and IHC analyses were examined independently in a blinded fashion.

\section{Flow Cytometry Studies}

Nine cases of MM with variable levels of CD138 staining intensity by FCM were identified. The BM aspirate specimens had been enriched for mononuclear cells by centrifugation over Ficoll-Plaque (Pharmacia, Piscataway, NJ). The cells $\left(10^{6}\right.$ in 100 $\mu \mathrm{L})$ were then incubated with $20 \mu \mathrm{L}$ phycoerythrinconjugated anti-CD138 (Becton Dickinson Immunocytometry Systems, San Jose, CA), $20 \mu \mathrm{L}$ PerCPconjugated anti-CD45 (Becton Dickinson), and 10 $\mu \mathrm{L}$ fluorescein isothiocyanate-conjugated CD138 
(Serotec) for 30 minutes at $4^{\circ}$; then washed and resuspended in $1 \%$ paraformaldehyde fixative. FCM was performed using a FACScan (Becton Dickinson, Mountain View, CA) equipped with an air-cooled argon laser. Data were analyzed using Cell-Quest software (Becton Dickinson). Gates were set around the $\mathrm{CD} 38^{+} \mathrm{CD} 45^{-} \mathrm{CD} 45^{\mathrm{dim}}$ quadrant to isolate the plasma cell population for evaluation of CD138 expression. Plasma cell clonality was confirmed by cytoplasmic light chain/DNA analysis (21). For this study, histograms of CD138 were divided at the log decade points of $10^{\circ}$ to $10^{2}$ and $10^{3}$ to $10^{4}$ to quantitate the percent plasma cells showing weakly positive and strongly positive staining, respectively.

\section{RESULTS}

\section{Immunohistochemistry}

Syndecan-1 was expressed exclusively on plasma cells and was not associated with endothelial cells, stromal cells or other hematopoetic elements in BM sections (Fig. 1A). Of the $28 \mathrm{BM}$ biopsies, only one biopsy that was extensively involved by moderately differentiated MM (Bartl grade II, asynchronous cell type) showed large areas with greater than $50 \%$ CD138-negative myeloma cells (Fig. 1B). This finding was confirmed on multiple repeat stainings of the biopsy. In addition, scattered positive MM cells served as an internal control. This case had an otherwise characteristic myeloma cell immunophenotype with absence of CD20 and CD45 expression by IHC and FCM, and bright CD38 staining with monotypic cytoplasmic kappa light chain by FCM. Two additional biopsies initially had large clusters of MM cells with absence of CD138. However, repeat staining showed weak expression. Therefore, 27 of the 28 biopsies exhibited immunoreactivity for CD138 in more than 95\% of MM cells, although rare cells (less than 5\%) in many cases lacked cell surface CD138 expression. Among the CD138positive MM cells, two populations with different staining qualities were observed. One population of cells had strong linear staining of the cytoplasmic membrane, but the other stained weakly with a disrupted pattern of membrane staining. MM cells with weak (or negative CD138) expression were cytologically indistinct from strongly positive cells in a given biopsy. In addition, the 27 cases with more than 95\% CD138-positive plasma cells included both well differentiated (Bartl grade I) and moderately differentiated (Bartl grade II) MM, suggesting that loss of syndecan-1 was not directly related to tumor differentiation. Surprisingly, deposits of CD138-positive material were evident within the extracellular matrix in fibrotic areas that contained myeloma cells (Fig. 1C). An increased proportion of

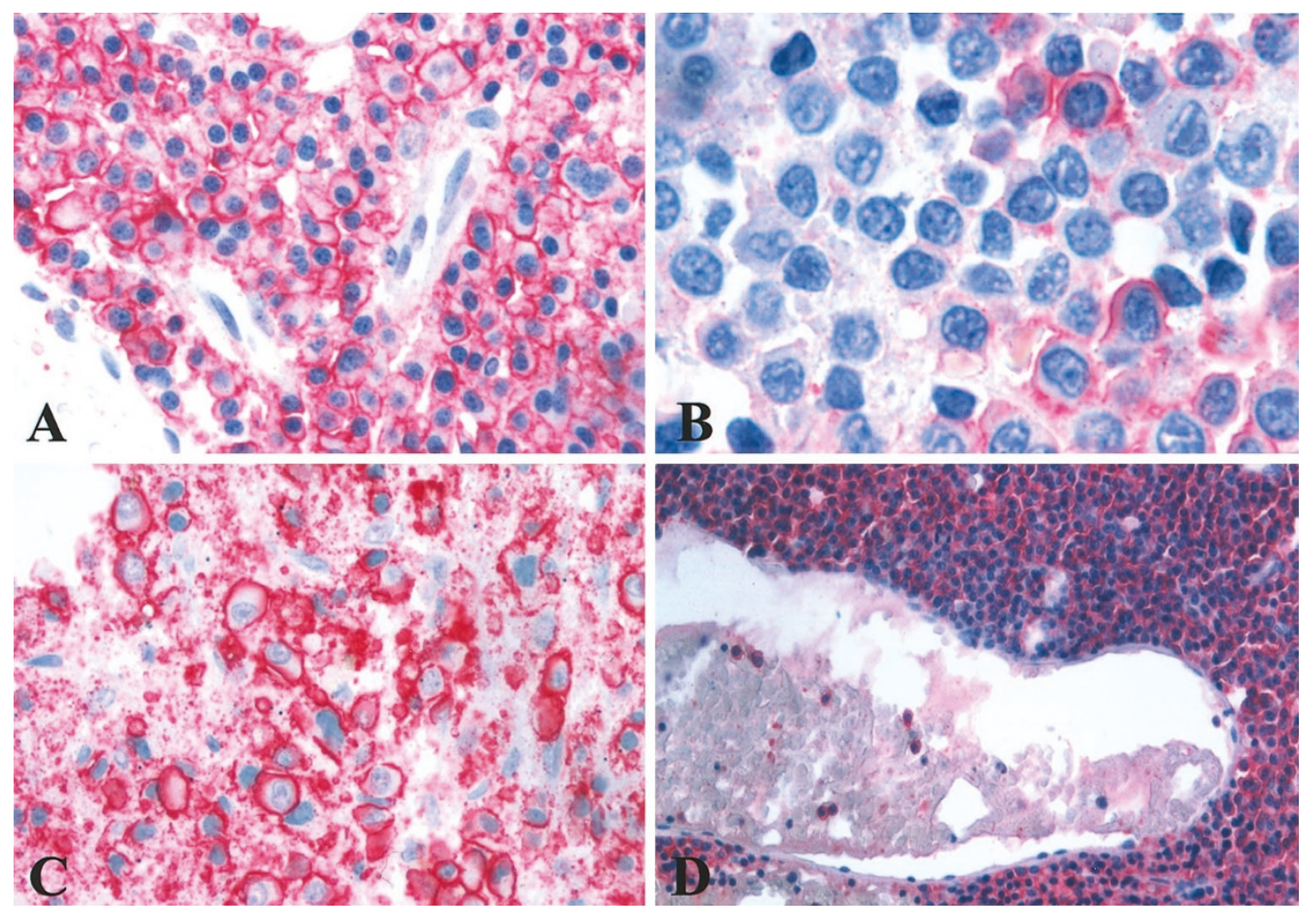

FIGURE 1. CD138 stains the majority of myeloma cells in BM biopsy sections (A, original magnification $500 \times$ ). A single patient exhibited absence of CD138 immunoreactivity in more than 50\% of myeloma cells (B). CD138-negative cells were cytologically indistinct from positive cells (original magnification $1000 \times$ ). Syndecan-1 deposition within the fibrotic extracellular matrix (C, original magnification $500 \times$ ). Intrasinusoidal and intravascular myeloma cells are CD138-positive (D, original magnification $200 \times$ ). 
MM cells in the fibrotic areas had a weak and disrupted pattern of membrane staining. Fibrosis was found when large clusters or sheets of myeloma were present in a paratrabecular, nodular or diffuse pattern of infiltration. In contrast, interstitial infiltrates were not associated with fibrosis and syndecan-1 deposition. Circulating MM cells, located within the lumens of blood vessels and sinuses also showed CD138 positivity (Fig. 1D).

\section{Flow Cytometry}

Nine cases with variations in CD138 staining intensity as determined by FCM were also examined by IHC. The BM biopsy morphologic and immunohistochemical findings for these cases are listed in Table 1. On FCM, myeloma cells were identified by gating on the $\mathrm{CD} 38^{+} \mathrm{CD} 45^{-} \mathrm{CD} 45^{\mathrm{dim}}$ cell population (Fig 2A). Three cases had $\geq 95 \%$ MM cells with strong CD138 staining intensity by FCM (Patients 1, 2, and 3). MM cells with weak CD138 expression ranged from $14 \%$ to $44 \%$ of the total plasma cells in the other six patients. Although CD138 weakly positive cells were identified by IHC evaluation, the percent was not as easily quantitated as by FCM. However, substantial deposition of CD138 in fibrotic areas of the BM stroma was associated with an increased number of MM cells showing weak CD138 expression by FCM. In the BM biopsy sections, a disproportionate number of MM cells in these fibrotic areas also had an irregular or disrupted pattern of weak CD138 membrane staining. FCM and IHC studies for Patient 1 , who had a majority of MM cells exhibiting strong CD138 staining are illustrated in Figure 2, B-C. Similarly, the studies for Patient 7 , who had a significant subpopulation of cells with weak CD138 staining by FCM, are shown in Figure 2, D-E. BM aspirate smears showed the MM cells from this patient (and Patient 9) had abundant cytoplasm with prominent vacuolation and cytoplasmic fraying. Reticulin stains confirmed moderate to marked reticulin fibrosis in cases with moderate to marked stromal CD138 deposition (Table 1, Fig. 3). Four of five cases (Patients 5 through 9) with more than $15 \%$ weakly staining CD138 MM cells by FCM had moderate to marked marrow reticulin fibrosis, in contrast to none of the four cases (Patients 1 through 4) with less than $15 \%$ weakly staining cells $(P<.05$, Fisher's Exact Test). In addition, all myeloma of polymorphous cell type were associated with marked reticulin fibrosis.

\section{DISCUSSION}

Within the BM of myeloma patients, CD138 (syndecan-1) was found to be a specific marker for plasma cells and was not present in association with other hematopoietic cells or endothelial cells. In 27 of the $28 \mathrm{MM}$ cases, greater than $95 \%$ of the plasma cells expressed CD138. The single case with a large population of CD138-negative cells had a BM biopsy packed with moderately differentiated MM cells (asynchronous cell type). Worsening cytologic differentiation among the MM cells in this case, and the others, which might predict for more aggressive potential was not associated with CD138 loss. In addition, in vitro studies have demonstrated that syndecan-1 mediates myeloma adhesion, and thus loss of syndecan-1 expression may precede intravascular invasion and extramedullary spread of $M M(1,2,22)$. We find that CD138 is expressed on cells within the intrasinusoidal spaces and lumen of vessels. This suggests that loss of syndecan- 1 is not required for cells to leave the marrow, or that expression is lost within the marrow and then regained as the cells circulate.

Rawstron et al. described differential expression of CD138 on MM cells, whereby circulating cells

TABLE 1. Evaluation of BM Histology in Nine Patients with MM-Correlation of CD138 Expression by Flow Cytometry Analysis and Immunohistochemistry

\begin{tabular}{|c|c|c|c|c|c|c|c|}
\hline \multirow{2}{*}{$\begin{array}{r}\text { Patient } \\
\text { Number }\end{array}$} & \multicolumn{3}{|c|}{ BM Biopsy } & \multicolumn{2}{|c|}{ Flow Cytometry } & \multicolumn{2}{|c|}{ Immunohistochemistry } \\
\hline & Plasma Cells (\%) & Bartl Grade (Cell Type) & Reticulin Score $^{a}$ & $\begin{array}{l}\text { Moderate-Strong CD } 138^{b} \\
\text { (\% MM Cells) }\end{array}$ & cIg, DNA Index & $\begin{array}{l}\text { Strong CD138 } \\
\text { Expression }^{c}\end{array}$ & $\begin{array}{l}\text { Stromal CD138 } \\
\text { Deposition }^{d}\end{array}$ \\
\hline 1 & 60 & II (asynchronous) & 2 & 97 & Lambda 0.97 & $2+$ & 0 \\
\hline 2 & 95 & II (asynchronous) & 1 & 96 & Карра 1.15 & $2+$ & $1+$ \\
\hline 3 & 40 & I (marschalko) & 2 & 95 & Lambda 0.97 & $3+$ & 0 \\
\hline 4 & 60 & II (asynchronous) & 2 & 86 & Карра 1.0, 1.24 & $2+$ & $1+$ \\
\hline 5 & 50 & II (polymorphous) & 3 & 84 & Lambda 1.91 & $2+$ & $2+$ \\
\hline 6 & 40 & II (asynchronous) & 1 & 79 & Lambda 1.0, 1.12 & $2+$ & $1+$ \\
\hline 7 & 70 & II (asynchronous) & 3 & 77 & Карра $0.94,1.80$ & $2+$ & $2+$ \\
\hline 8 & 70 & II (polymorphous) & 3 & 75 & Карра 1.0, 1.92 & $2+$ & $2+$ \\
\hline 9 & 95 & II (polymorphous) & 4 & 56 & Kappa 1.0, 1.77 & $1+$ & $2+$ \\
\hline
\end{tabular}



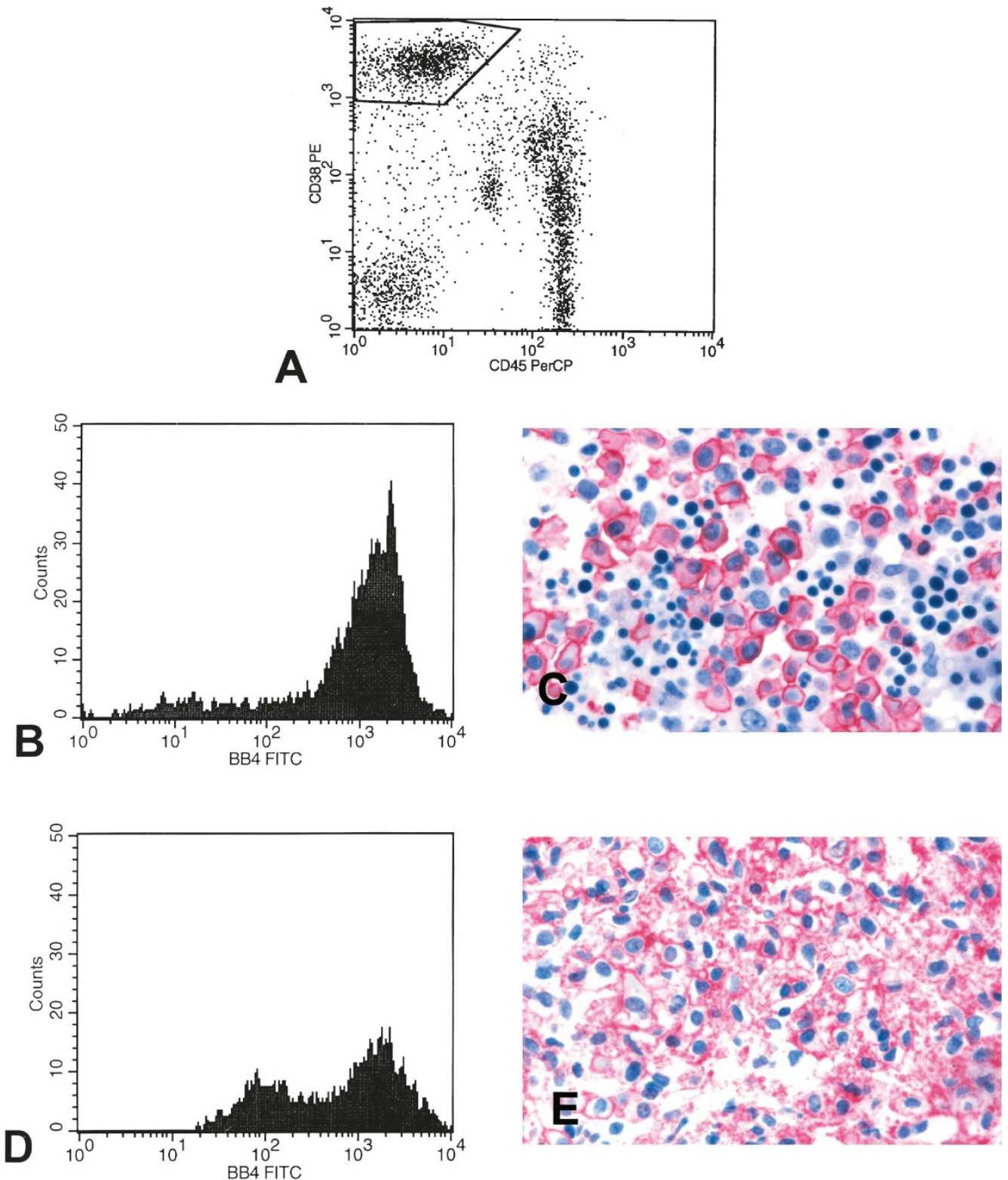

FIGURE 2. FCM analysis of BM shows the gate around the $\mathrm{CD}^{+} 8^{+} \mathrm{CD} 45^{-} \mathrm{CD} 45^{\mathrm{dim}}$ cells used to isolate the myeloma cell population (A). FCM histogram of BM from Patient 1 shows strong CD138 expression in the majority of myeloma cells (B). BM biopsy section from Patient 1 confirms strong CD138 immunoreactivity by myeloma cells (C, original magnification, 500x). FCM histogram of BM from Patient 7 shows two distinct peaks of CD138 staining intensity on myeloma cells, consistent with weak and strong CD138 expression (D). BM biopsy section from Patient 7 displays a significant subpopulation of myeloma cells with weak CD138 immunoreactivity in a background of fibrosis (E, original magnification $500 \times$ ).
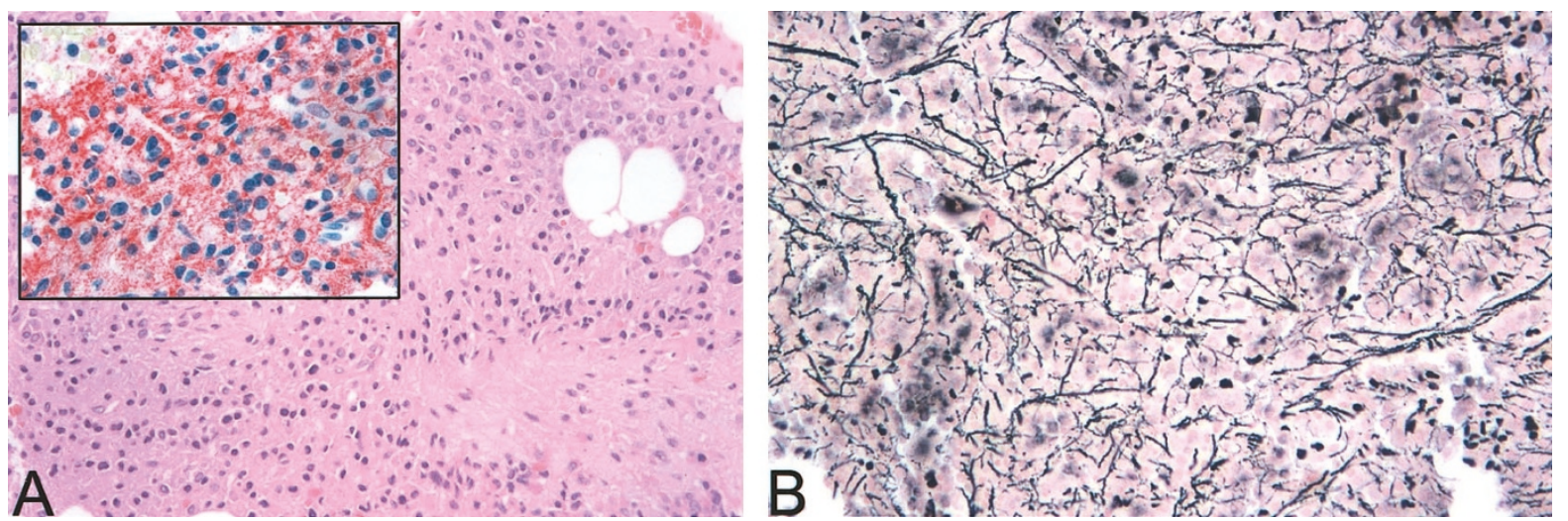

FIGURE 3. BM biopsy section of MM with stromal fibrosis from Patient 9 (A, original magnification, $200 \times$ ). Inset shows CD138 immunoreactivity $($ B, original magnification $500 \times$ ). A reticulin stain highlights the marked reticulin fibrosis $(\mathbf{C}$, original magnification $200 \times$ ). 
expressed lower levels of CD138 than their BM counterparts (23). Wijdenes et al. found that CD138 recognized only about $70 \%$ of myeloma cells by FCM, possibly due to shedding of syndecan- 1 before the analysis (24). Jourdan et al. confirmed that apoptotic primary myeloma cells lose CD138 after harvesting and storage at room temperature, whereas viable myeloma cells retain CD138 (15). Our finding of CD138 staining by a majority of MM cells, using both IHC and FCM, indicates technical issues may have been a problem in previous reports. However, when IHC was performed on biopsy sections from nine cases with varying intensities of CD138 staining by FCM, we confirmed heterogeneous CD138 expression on MM cells in situ. FCM was more sensitive than IHC in separating weakly from strongly positive cells. Nonetheless, sampling differences between BM biopsy and aspirate specimens most likely explains the differences observed between the IHC versus FCM results. Furthermore, increased stromal syndecan-1 deposition and reticulin fibrosis in biopsy sections was associated with a higher percentage of $\mathrm{MM}$ cells showing weak CD138 by FCM.

Explanations for a population of MM cells that weakly express CD138 include therapy effect, apoptosis, decreased syndecan-1 synthesis, and increased shedding of syndecan- 1 from the cell surface. Jourdan et al. found dexamethasone-induced apoptosis of myeloma cells was associated with loss of CD138 (15). Although the majority of patients in our study had received previous therapy, often before coming to our institution, the myeloma cells appeared viable and showed strong CD138 staining. The single case with loss of CD138 in a majority of cells was associated with an aggressive disease course and the patient died shortly after the biopsy. In addition, a defect in plasma cell apoptosis has been described in MM, whereby decreased rather than increased apoptosis appears to be a factor in progression to overt myeloma and advancement of disease (25). Although decreased CD138 synthesis cannot be entirely excluded, the most likely explanation for a weak CD138 population of MM cells is shedding of the syndecan-1 ectodomain. Syndecan-1 shedding is usually highly regulated but can be accelerated in areas of tissue injury by release of growth factors or proteases (26). In the BM biopsy specimens, the weaker staining MM cells had a disrupted pattern of membrane staining and were found preferentially in areas of fibrosis.

Importantly, we demonstrate for the first time, that fibrotic stroma associated with MM shows increased CD138 immunoreactivity that is not associated with fibroblast or myeloma cell surfaces. The fact that CD138 was present as relatively large deposits, was associated with MM cells showing a weak and disrupted pattern of CD138 expression, and was isolated to the areas with marked reticulin fibrosis, suggests that staining for syndecan-1 is not an artifact. Instead, it is likely that shed syndecan-1 is trapped within the extracellular matrix, similar to a report of syndecan-1 within stromal tissue of infiltrating ductal carcinoma of the breast (27). Although the fibrosis is most likely due to cytokine production, similar to the process that occurs in tissue injury, many of the same cytokines also promote angiogenesis, tumor growth, and invasion (28). It is likely that the shed syndecan-1 or its degradation products regulate heparin-binding growth factors in this process. For example, heparinmediated FGF-2 mitogenesis is normally inhibited by soluble syndecan-1 ectodomains (29). When heparinases are released in sites of injury and inflammation, they can degrade syndecan-1 producing heparin-like heparan sulfated fragments that are potent mitogenic activators for FGF-2. The finding of higher levels of FGF-2 in plasma cell extracts from patients with active $\mathrm{MM}$ than in nonactive MM or monoclonal gammopathy of undetermined significance supports this theory (30). Furthermore, BM fibrosis is associated with increased microvessel density in biopsies of $\mathrm{MM}$ and both increased microvessel density and increased circulating syndecan- 1 levels are associated with decreased patient survival $(14,31,32)$. Thus, syndecan-1 shedding, fibrosis, and angiogenesis are likely intertwined. Moreover, the syndecan-1 within the fibrotic marrow may provide a reservoir of growth factors that drives re-emergence of the tumor after chemotherapy.

In conclusion, we find that syndecan- 1 is present on the majority of MM cells within the BM and is not expressed by other benign hematopoietic elements or by endothelium. CD138 expression in MM is independent of cytologic differentiation or intravascular invasion. The identification of a single case with a large population of CD138-negative MM cells suggests that utilizing CD138 for purifying MM cells from clinical specimens, especially stem cell products, may be problematic in some patients. MM cells exhibiting weakly positive CD138 staining were present in many cases, often in association with tumor fibrosis. Lastly, the important observation that syndecan-1 accumulates within fibrotic areas of the BM, raises the possibility that these areas act to store and regulate the activity of heparinbinding growth factors, and perhaps contribute to the pathogenesis and persistence of the tumor.

Acknowledgment: This work was supported in part by a National Institutes of Health grant CA55819 and CA68494 (to RDS).

\section{REFERENCES}

1. Ridley RC, Xiao H, Hata H, Woodliff J, Epstein J, Sanderson R. Expression of syndecan-1 regulates human myeloma plasma cell adhesion to type I collagen. Blood 1993;81:767-74. 
2. Liebersbach BF, Sanderson RD. Expression of syndecan-1 inhibits cell invasion into type-I collagen. J Biol Chem 1994; 268:20013-9.

3. Stanley MJ, Leibersbach BF, Liu W, Anhalt DJ, Sanderson RD. Heparan sulfate-mediated cell aggregation. Syndecans-1 and -4 mediate intercellular adhesion following their transfection into human B lymphoid cells. J Biol Chem 1995;270: 5077-83.

4. Dhodapkar MV, Abe E, Theus A, Lacy M, Langford JK, Barlogie B, et al. Syndecan-1 is a multifunctional regulator of myeloma pathobiology; control of tumor survival, growth, and bone cell differentiation. Blood 1998;91:2679-88.

5. Costes V, Magen V, Legouffe E, Durand L, Baldet P, Rossi JF, et al. The Mi15 monoclonal antibody (anti-syndecan-1) is a reliable marker for quantifying plasma cells in paraffinembedded bone marrow biopsy specimens. Human Pathol 1999;30:1405-11.

6. Wijdenes J, Voous WC, Clement C, Post J, Morard F, Vita N, et al. A plasmacyte selective monoclonal antibody (B-B4) recognizes syndecan-1. Br J Haematol 1996;94:318-23.

7. Chilosi M, Adami F, Lestani M, Montagna L, Cimarosto L, Semenzato G, et al. CD138/syndecan-1: a useful immunohistochemical marker of normal and neoplastic plasma cells on routine trephine bone marrow biopsies. Mod Pathol 1999;12:1101-6.

8. Pellat-Deceunynck C, Bataille R, Robillard N, Harousseau JL, Rapp MJ, Juge-Morineau N, et al. Expression of CD28 and CD40 in human myeloma cells: a comparative study with normal plasma cells. Blood 1994;84:2597-603.

9. Witzig T, Kimlinger T, Ahmann G, Katzmann J, Greipp P. Detection of myeloma cells in the peripheral blood by flow cytometry. Cytometry 1996;26:113-20.

10. Schneider U, van Lessen A, Huhn D, Serke S. Two subsets of peripheral blood plasma cells defined by differential expression of CD45 antigen. Br J Haematol 1997;97:56-64.

11. Rawstron AC, Owen RG, Davies FE, Johnson RJ, Jones RA, Richards SJ, et al. Circulating plasma cells in multiple myeloma: characterization and correlation with disease stage. Br J Haematol 1997;97:46-55.

12. Dhodapkar MV, Kelly T, Theus A, Athota AB, Barlogie B, Sanderson RD. Elevated levels of shed syndecan-1 correlate with tumor mass and decreased matrix metalloproteinase- 9 activity in the serum of patients with multiple myeloma. Br J Haematol 1997;99:368-71.

13. Seidel C, Borset M, Hjertner O, Cao D, Abildgaard N, HjorthHansen $\mathrm{H}$, et al. High levels of soluble syndecan-1 in myeloma-derived bone marrow: modulation of hepatocyte growth factor activity. Blood 2000;96:3139-46.

14. Seidel C, Sundan A, Hjorth M, Turesson I, Dahl IM, Abildgaard N, et al. Serum syndecan-1: a new independent prognostic marker in multiple myeloma. Blood 2000;95:388 92.

15. Jourdan M, Ferlin M, Legouffe E, Horvathova M, Liautard J, Rossi JF, et al. The myeloma cell antigen syndecan-1 is lost by apoptotic myeloma cells. Br J Haematol 1998;100:637-46.

16. Bartl R, Frisch B, Burkhardt R, Fateh-Moghadam A, Mahl G, Gierster $\mathrm{P}$, et al. Bone marrow histology in myeloma: its importance in diagnosis, prognosis, classification, and staging. Br J Haematol 1982;51:361-75.

17. Bauermeister DE. Quantitation of bone marrow reticulin-a normal range. Am J Clin Pathol 1971;56:24-31.
18. Dore JM, Morard F, Vita N, Wijdenes J. Identification and location on syndecan-1 core protein of the epitopes of B-B2 and B-B4 monoclonal antibodies. FEBS Lett 1998;426:67-70.

19. Hayashi K, Hayashi M, Jalkanen M, Firestone JH, Trelstad RL, Bernfield M. Immunocytochemistry of cell surface heparan sulfate proteoglycan in mouse tissue. A light and electron microscopic study. J Histochem Cytochem 1987;35: 1079-88.

20. Inki P, Larjava H, Haapasalmi K, Miettinen HM, Grenman R, Jalkanen M. Expression of syndecan-1 is induced by differentiation and suppressed by malignant transformation of human keratinocytes. Eur J Cell Biol 1994;63:43-51.

21. Barlogie B, Alexanian R, Pershouse M, Smallwood L, Smith L. Cytoplasmic immunoglobulin content in multiple myeloma. J Clin Invest 1985;76:765-9.

22. Teoh G, Anderson KC. Interaction of tumor and host cells with adhesion and extracellular matrix molecules in the development of multiple myeloma. Hematol Oncol Clin North Am 1997;11:27-42.

23. Rawstron A, Barrans S, Blythe D, Davies F, English A, Pratt G, et al. Jack A. Distribution of myeloma plasma cells in peripheral blood and bone marrow correlates with CD56 expression. Br J Haematol 1999;104:138-43.

24. Wijdenes J, Clement C, Klein B, Dore J. CD138 cluster report. In: Kishimoto T, editor. Leukocyte Typing VI: Proceedings of the Sixth International Workshop and Conference on $\mathrm{Hu}$ man Leukocyte Differentiation Antigens. New York: Garland; 1996. p. 249-52.

25. Witzig TE, Timm M, Larson D, Therneau T, Greipp PR. Measurement of apoptosis and proliferation of bone marrow plasma cells in patients with plasma cell proliferative disorders. Br J Haematol 1999;104:131-7.

26. Subramanian SV, Fitzgerald ML, Bernfield M. Regulated shedding of syndecan- 1 and -4 ectodomains by thrombin and growth factor receptor activation. J Biol Chem 1997;272: 14713-20.

27. Stanley MJ, Stanley MW, Sanderson RD, Zera R. Syndecan-1 expression is induced in the stroma of infiltrating breast carcinoma. Am J Clin Pathol 1999;112:377-83.

28. Mason IJ. The ins and outs of fibroblast growth factors. Cell 1994;78:547-52.

29. Kato M, Wang H, Kainulainen V, Fitzgerald ML, Ledbetter S, Ornits DM, et al. Physiological degradation converts the soluble syndecan-1 ectodomain from an inhibitor to a potent activator of FGF-2. Nature Med 1998;4:691-7.

30. Vacca A, Ribatti D, Presta M, Minischetti M, Iurlaro M, Ria R, et al. Bone marrow neovascularization, plasma cell angiogenic potential, and matrix metalloproteinase-2 secretion parallel progression of human multiple myeloma. Blood 1999;93:3064-73.

31. Wilson CS, Munshi NC, Waldron J, Bullard LE, Singhal S, Barlogie B, et al. Correlation of bone marrow (BM) microvessel density (MVD) to histology in multiple myeloma (MM) [abstract]. Mod Pathol 1999;12:149.

32. Munshi NC, Wilson CS, Penn J, Epstein J, Singhal S, Hough A, et al. Angiogenesis in newly diagnosed multiple myeloma: poor prognosis with increased microvessel density (MVD) in bone marrow biopsies [abstract]. Blood 1998; 92(Suppl. 1):98. 